\title{
Intravascular ultrasound imaging of recanalized spontaneous coronary artery dissection managed with percutaneous coronary intervention
}

\section{Boris Starčević, Ante Lisičić*}

University Hospital Dubrava, Zagreb, Croatia
RECEIVED:

February 10, 2016

ACCEPTED:

February 20, 2016

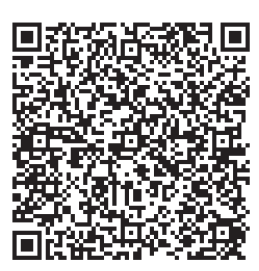

KEYWORDS: spontaneous coronary artery dissection, intravascular ultrasound, percutaneous coronary intervention.

CITATION: Cardiol Croat. 2016;11(3-4):120. | DOI: http://dx.doi.org/10.15836/ccar2016.120

*ADDRESS FOR CORRESPONDENCE: Ante Lisičić, Klinička bolnica Dubrava, Avenija Gojka Šuška 6 , HR-10000 Zagreb, Croatia. / Phone: +385-91-571-0116 / E-mail: antelisicic1980@gmail.com

ORCID: Boris Starčević, http://orcid.org/0000-0002-3090-2772 • Ante Lisičić, http://orcid.org/0000-0002-4365-9652

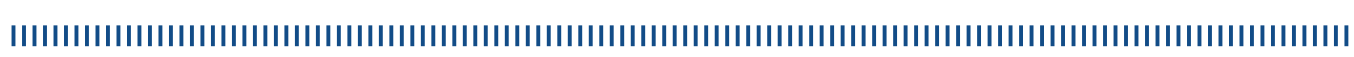

The spontaneous coronary artery dissection is generally seldom in clinical practice. ${ }^{1}$

We present a 41-year-old male who was admitted because of high arterial blood pressure and chest pain. The patient's risk factors were smoking, dyslipidemia and poorly controlled arterial hypertension. His 12-lead electrocardiogram on admission showed discrete ST-segment elevation and negative T-waves in anterior and lateral leads and Q-waves in inferior leads. Initial laboratory results revealed a slightly elevated troponin I, but other cardiac bio-markers were negative. Echocardiography showed marginally dilated left ventricle and left atrium, preserved global ejection fraction of left ventricle with regional wall motion abnormality involving apex and intraventricular septum. Coronary angiogram revealed a peculiar beaded-like appearance in middle segment of left anterior descending artery and similar finding in proximal segment of right coronary artery, but without angiographically evident stenosis. To further define the nature of the filling defects, an intravascular ultrasound (IVUS) was performed which showed dissection flaps with multiple false lumens involving middle left anterior descending artery (LAD) and proximal right coronary artery (RCA), a finding that indicates recanalized spontaneous coronary artery dissection. A successful percutaneous coronary intervention with drugeluting stents was done to the LAD and RCA with excellent angiographic result that was confirmed on repeated IVUS. The patient was discharged several days after the intervention with dual antiplatelet therapy, antihypertensive and antihyperlipidemic therapy. He was symptom-free and without any clinical sequelae in the follow-up.

Hereby, an IVUS helped us in confirming the filling defects to be recanalized spontaneous coronary artery dissections and also in assessing the length of the lesions and in deciding the correct size of the stents to adequately cover the diseased segments.

1. Das Neves BC, Núñez-Gil IJ, Alfonso F, Hernández R, Cuevas C, Jimenez Quevedo P, et al. Evolutive recanalization of spontaneous coronary artery dissection: insights from a multimodality imaging approach. Circulation. 2014;129(6):719-20. DOI: http://dx.doi.org/10.1161/CIRCULATIONAHA.112.000101 